\title{
Kierkegaard's point of view on Luther in his Journals
}

\section{[El punto de vista de Kierkegaard sobre Lutero en sus Diarios]}

\author{
Jose Garcia Martin - Dinara G. Vasbieva - Jozef Polacko \\ - Hedviga Tkacova
}

DOI: 10.18355/XL.2020.13.03.04

\begin{abstract}
Through a selection of texts from the Kierkegaard's Journals, an analysis is made of the Danish theologian's criticism and father of the Protestant Reformation: Luther. Starting with the figure of Socrates, the article looks at the most important aspects of this critique: the concept of the Reformation, the relationship to the Holy Scriptures and the concept of Christianity, the Christian-political relationship, the conditions of martyrdom and imitation, and the role of divine Grace. The conclusion is that while Luther can be understood as a corrective to the Christianity of his time, Kierkegaard was also a corrective to his own time.
\end{abstract}

Key words: Luther, Christianity, reformer, martyr, model, grace

\section{Resumen}

A través de una selección de textos de los Diarios de Kierkegaard, se lleva a cabo un análisis de la crítica del teólogo danés sobre el padre de la Reforma protestante: Lutero. Partiendo de la figura de Sócrates, el artículo examina los aspectos más importantes de dicha crítica: el concepto de reforma, la relación con las Sagradas Escrituras y el concepto de cristianismo, la relación cristianismo-política, las condiciones del martirio e imitación, y el papel de la gracia divina. La conclusión a la que se llega es que, si bien Lutero se puede entender como un correctivo al cristianismo de su época, también Kierkegaard lo fue con respecto al suyo.

Palabras clave: Lutero, cristianismo, reformador, mártir, modelo, gracia

\section{Introducción}

"Naar Protestantismen skal være Andet and et i givet Øieblik fornødent Correctiv, er den saa ikke egentlig det Menneskeliges Opstand mod Christendommen?"

("Si el protestantismo tiene que ser algo más que un correctivo necesario en un momento dado, ¿no es ciertamente una rebelión de la humanidad contra el cristianismo?") (Kierkegaard, 1968-1978: XI 1 A 76/1997-2013: NB29:27).

Aunque es bien conocida la influencia del pensamiento y la obra de Kierkegaard sobre la teología alemana (Barth, Bonhoeffer, Tillich; cf. Barret, 1981: 335-376; Valco, 2017: 47-58), no ocurre lo mismo con relación a lo que piensa Kierkegaard sobre el padre de la Reforma Protestante, Martin Lutero y la relación entre ambas ilustres figuras del protestantismo (un estudio recomendable para ello sería el de J. Sløk, 1962: 66-76, o bien Prender, 1981: 121-172, si se quiere ver un estudio sobre la relación de Lutero con Kierkegaard, tanto en su obra publicada, como con respecto a sus Diarios). No, al menos, ateniéndonos a lo que podamos encontrar al respecto en sus Diarios (Dagbøger). Lo que sí resulta evidente en el campo de dicha teología es el reconocimiento de Kierkegaard como una influencia significativa en los grandes teólogos teutones contemporáneos; comparable a figuras tan centrales como San

XLinguae, Volume 13 Issue 3, June 2020, ISSN 1337-8384, ISSN 2453-711X 
Pablo, San Agustín, o el propio Lutero. Sin embargo, parece un tanto contradictorio, o al menos llamativo, equiparar a Kierkegaard con Lutero; me refiero a ello por la fuerte carga crítica que podemos encontrar en el pensamiento kierkegaardiano contra el cristianismo protestante de su época; sobre todo, en 1854-1855 con la publicación de su revista Øjeblikket (El instante, 2006: 169-179). Como también resulta un tanto sorprendente que el cristianismo protestante (como cualquier otro que apele al Nuevo Testamento) asuma, admire y haga suyo, como un hijo más del luteranismo, a su más contumaz crítico (sobre todo, en sus últimos días). Lo que parece indicar tal hecho es que la figura de Kierkegaard ha sido asimilada intelectualmente, pero no tanto existencial o espiritualmente. En cualquier caso, es indudable que el melancólico danés y escritor religioso supone un reto para cualquier conciencia cristiana. Justamente en la misma proporción que el cristianismo en cuanto tal representa la más alta medida para todo ser humano.

\section{El modelo socrático}

Para entender el punto de vista kierkegaardiano sobre Lutero, hay que empezar recordando que el danés tuvo en gran estima la figura de Sócrates, al que dedicó su tesis doctoral Om Begrebet Ironi med stadigt Hensyn til Sócrates (Sobre el concepto de ironía con referencia constante a Sócrates, 1841; edición en español, Kierkegaard, 2000: 60-342). Para Kierkegaard, Sócrates representa el auténtico paradigma de intelectual honrado y leal, como el propio danés lo fue. Hasta tal punto, que a Kierkegaard se le puede considerar una especie de Sócrates del norte. Un Sócrates, no pagano, sino cristiano, aunque igualmente crítico con la sociedad y la cultura de su época.

De la misma manera que Sócrates, a través de la "ironía", pretendió desenmascarar a sus conciudadanos de su falso saber acerca de los problemas ético-políticos, Kierkegaard hizo otro tanto, pero en el ámbito religioso cristiano con respecto a lo que significa ser un verdadero cristiano, o en qué consiste el auténtico cristianismo, qué es, frente a la Cristiandad luterana y protestante. En ese sentido, tanto uno como otro, Sócrates y Kierkegaard, apelaron a la voz interior de su propia conciencia: el primero a su "daimon" particular, el segundo a la de su amor al cristianismo. Precisamente, la honestidad de la que hablaba debe entenderse como la fidelidad a dicha llamada "divina".

Según Kierkegaard, Sócrates fue un verdadero "reformador" (además de un héroe y un mártir). Los tres aspectos están estrechamente relacionados entre sí y con la categoría de singularidad. Ser un verdadero reformador no consiste en abatir a un Papa o a un Rey, luchar contra ellos; no se trata de ir en contra de un individuo importante, sino de enfrentarse a la muchedumbre, a la masa, al público. No es una cuestión política, sino espiritual. Y espiritualmente la vida requiere sacrificios y sufrimientos; demanda hacer conscientes a los hombres de su ser individual y de su responsabilidad moral como tales, aunque haya que enfrentarse a todos ellos.

Así pues, Sócrates ha sido el único reformador (Kierkegaard, 1968-1978: VIII 1 A 123/1997-2013: NB2:16); los demás no, aun siendo entusiastas y bienintencionados, incluido el Padre de la Reforma Protestante: Lutero. Kierkegaard ve como una gran irregularidad en él su actitud política de no atacar a la multitud, sino a un individuo singular eminente: el Papa. Según Kierkegaard, tal planteamiento hizo que su lucha fuera fácil, porque la multitud solo deseaba sacudirse las cargas. La libertad por la que disputaba debía haber hecho la vida espiritual más difícil que la anterior. Pero entonces nadie le hubiera seguido. Si lo que Lutero quería era simplemente abolir al Papa, estupendo, piensa Kierkegaard; sin embargo, esto no deja de ser un puro comercio político. No obstante, Kierkegaard también expresa claramente que Lutero le merece toda su consideración y respeto (Kierkegaard, 1968-1978: X 2 A 559/19972013: NB16:87). 
Kierkegaard cuestiona, además, el hecho de que Lutero creara una nueva secta (conjunto de fieles) cristiana con sus seguidores, en vez de defender y asumir existencialmente el verdadero cristianismo de forma solitaria enfrentándose a todos; la consecuencia fue, de nuevo, la letanía y la exterioridad, algo que precisamente Lutero criticaba de la Iglesia en su época. De todos modos, lo califica como un gran hombre. También critica la falta de claridad de la predicación de Lutero en algunos aspectos y su falta de concordancia con su vida, aunque actuara correctamente. Su conclusión es que fue mejor su doctrina que su vida (Kierkegaard, 1968-1978: X 2 A 263/19972013: NB14:88).

\section{Lutero y las Sagradas Escrituras}

Pero ¿cómo escuchar a la divinidad?; en definitiva, ¿cómo conocer la voluntad de Dios? Obviamente conociendo sus palabras, su mensaje. No se trata de que en cada momento podamos preguntarle, sino de prestar atención y escuchar lo que nos ha dicho en las Sagradas Escrituras. Lo que sucede es que la voluntad de Dios se predica en abstracto y cada uno de nosotros debemos comprenderla in concreto. Tenemos que destacar aquí la clara influencia de Lutero sobre Kierkegaard. Las Sagradas Escrituras deben ser leídas directamente, sin comentario alguno de tercera persona, como si fuera la carta de nuestra amada; porque en realidad, los Evangelios son cartas de amor de Dios al ser humano ("Kjerligheds-Breve"; Kierkegaard, 1968-1978: XI 2 A 51/1997-2013: NB32:132). De otra formam sería una relación contra naturam con ellas (Kierkegaard, 1968-1978: X 2 A 555/1997-2013: NB16:84). Y no es cuestión de que puedan ser entendidas por personas doctas, ya que, según el pensador danés, el Nuevo Testamento está escrito para ser comprendido fácilmente (Kierkegaard, 19681978: X 3 A 34/1997-2013: NB17:102). En lo tocante a esto, importa señalar, además, que la dogmática cristiana no debe desarrollar la doctrina de Jesucristo, puesto que el mensaje estaba en su vida, en su actividad (Kierkegaard, 1968: I A 27 y 28/19972013: Papir 55:1 y Papir 55:2). La misma cientificidad teológica se equivoca cuando emplea categorías directas, racionales; lo verdaderamente importante no es que se llegue a un acuerdo - aunque sea con respecto a lo más fundamenta - sobre las Sagradas Escrituras, sino la fe o creencia. Incluso debe haber desacuerdo para que tenga sentido dicha fe y la posibilidad del escándalo. En el sentido ético, la manera de entender kierkegaardiana la relación entre trascendencia y subjetividad hay que referirla al concepto de verdad; por tanto, es una cuestión de interioridad y congruencia existencial con nuestra fe cristiana.

Por otro lado, al leer el Nuevo Testamento con ese lenguaje tan fuerte, tan tajante, la mayoría piensa, al ser tan infinitamente elevado, que no debe tomarse de forma literal, tan en serio, considerándolo simplemente una forma de hablar. Pero este es un planteamiento equivocado para Kierkegaard. Porque mientras más significativo o importante es un ser humano, mayor valor posee su palabra y menos es una simple manera de hablar. Escribe Kierkegaard (1968-1978: XI 1 A 65/1997-2013: NB29:16): "La ley es: cuanto más insignificante es el que habla, lo dicho es más bien una forma de hablar; cuanto más importante, menos es una forma de hablar. De este modo, la situación es más bien que Dios es el único del que, de ninguna manera, se puede decir que lo que dice sea una forma de hablar, sino que hay que tomarlo literalmente. Lo majestuoso está justo en hablar literalmente la verdad. Exagerar (esto es quizá solamente una forma de hablar) no es apropiado para las majestades, menos para la majestad absoluta." ("Loven er: jo Ubetydeligere den Talende, jo snarere er det Udsagte vel Talemaade, jo Betydeligere, desto mindre er det Talemaade. Saaledes bliver Forholdet snarest det, at Gud er den Eneste, hvor der ubetinget ikke kan være Tale om, at det skulde være Talemaade hvad han siger; men hvor det just er at tage ganske bogstaveligt. Det Majestætiske er netop at tale bogstaveligt sandt. At overdrive

XLinguae, Volume 13 Issue 3, June 2020, ISSN 1337-8384, ISSN 2453-711X 
("det er vel kun en Talemaade" hvad han siger) egner sig ikke for Majestæter mindst for den absolute Majestæt.")

Parece evidente, pues, que Kierkegaard apelaba a cierto principio de autoridad máxima expresada en las mismas Escrituras Sagradas, único criterio espiritual al respecto. Y parece evidente también que para el teólogo danés la hermenéutica de los textos sagrados vendría a ser un puro prurito inútil y sin sentido.

\section{Lutero y Kierkegaard frente al cristianismo}

Según Kierkegaard, el cristianismo es una comunicación de existencia y no una teoría. Es una forma de existir que, evidentemente, implica una manera de entender la vida. El problema es de índole práctico esto es, el problema de cuál sea la relación del individuo con los ideales cristianos. No se trata, pues, de un problema de conocimiento intelectual, sino que se trata de un "ser-capaz" (kunnen), de una transformación o conversión existencial (Kierkegaard, 1968-1978: X 2 A 606/19972013: NB17:33; cf. también el opúsculo kierkegaardiano La dialéctica de la comunicación ética y ético-religiosa, 2018: 89-101). Por eso, no debe aprenderse la doctrina cristiana como algo mecánico y de memoria. Esto hace que la enseñanza de la fe cristiana no pueda ser como la de cualquier otra materia, puesto que debe influir en la existencia (Kierkegaard, 1968-1978: X 4 A 289/1997-2013: NB24:44). En palabras de B. Sáez Tajafuerce (1999: 99): “Kierkegaard's main critical point in this discussion is that both science and scholarship are unable to ridge "ideality" and "reality", and thus, allow these ethical truths to escape mere thought and enter into actual existence, simply because science and scholarship are indifferent to "the task" and, hence, indifferent towards existence, and/or action [...]. Hence, what must be conveyed in this realm is not information or knowledge but an ability or being-able."

Hay que buscar las condiciones del cristianismo, pero del verdadero cristianismo, que según el Evangelio son: el espíritu, el martirio, la imitación y la relación con Dios. Sin ellas, no puede decirse que el individuo es cristiano. Por eso, también se resumen todas ellas en la condición de la singularidad. La ausencia de esos requisitos vició a la cristiandad protestante, haciendo a ésta entrar en contradicción directa con el cristianismo. El problema, pues, es buscar las verdaderas condiciones de realización práctica del cristianismo, las cuales están amenazadas por todos los factores de despersonalización que ponen a prueba nuestra singularidad: por la sociabilidad mal entendida (la masa), el orden socialmente establecido (la cristiandad) y el anonimato, manipulación y engaños de los medios de comunicación de masas (Pavlikova - Zalec, 2019: 1015-1026; Kondrla-Durkova, 2018: 45-50). Podríamos afirmar, pues, que Kierkegaard fue una especie de "antisistema" en su época.

Kierkegaard criticó a Lutero como responsable, en parte, de dicha situación. Pero también criticó al obispo Jakob P. Mynster (máximo representante de la Iglesia Nacional Danesa), así como al teólogo contemporáneo de Kierkegaard y creador de las escuelas populares danesas, N. F. S. Grundtvig (1783-1872). La crítica a Mynster fue realizada de forma abierta y polémica en la última etapa de su vida (Garcia Martin, 2011: 209-214), una vez desaparecido este último (al que, por otro lado, conocía desde joven al ser visitante asiduo a las tertulias que convocaba su padre en la casa familiar de Nytorv, profesándole cierta admiración y respeto), por la figura de Hans L. Martensen (sucesor de Mynster, teólogo hegeliano y profesor de Kierkegaard en la Universidad de Copenhague). Con toda seguridad, semejante lucha extenuó física y psíquicamente a Kierkegaard hacia el final de su vida, debilitando su salud ,a la vez que se agotaban los recursos económicos de su herencia paterna.

\section{Cristiandad versus cristianismo}

La figura de Lutero, pues, resulta imprescindible para entender la crítica de Kierkegaard al cristianismo de su época o cristiandad ("Christenheden"). A pesar de expresar, como he dicho anteriormente, su respeto por él en los Diarios (Dagbøger), 
Kierkegaard no dejó de reprobar su actuación. En primer lugar, por su responsabilidad al sustituir el Papa por el público, y cambiar el concepto de martirio (Kierkegaard, 1968-1978: XI 1 A 108/1997-2013: NB29:59). Lutero alteró el cristianismo modificando el martirio (Kierkegaard, 1968-1978: XI 2 A 161/1997-2013: NB34:20), causando un gran daño justo por no haber llegado a ser mártir (Kierkegaard, 19681978: XI 1 A 61/1997-2013: NB29:12). El verdadero martirio, tal como lo entiende Kierkegaard, es el martirio de sangre, aquel que sufrieron justamente los primeros cristianos. En términos generales, para Kierkegaard su error estuvo en confundir el hecho de ser paciente con ser médico; a Lutero le faltaba la claridad del médico (Kierkegaard, 1968-1978: XI 1 A 193/1997-2013: NB30:22) y, por tanto, parece que no era el más indicado para proponer ningún "remedio" a la situación de la iglesia en su época. Además, fue una desgracia la generalización de algo que venía a responder a una situación dada y concreta.

Por otra parte, Lutero también causó un gran perjuicio al tener admiradores que le adoraban. Cuando lo que requiere el cristianismo son imitadores; pero imitadores o seguidores del Hijo de Dios hecho hombre. Lo peor de todo fue la confusión que originó, respecto a lo que significa ser reformador, al haberse ayudado de la política, como ya he dicho anteriormente: "Su tentación ha sido echar mano del poder secular del Estado para vencer. Pero al hacer eso, se han perdido, han sido infieles a su misión. Han dejado el poder de Dios, que se manifiesta en la debilidad y en la persecución para tomar el del mundo, que es dominio, influjo y prepotencia" (Suances Marcos, 1998: 249). "El resultado ha llegado a ser la desorientación más profunda en los conceptos más elevados, y la desmoralización más peligrosa de todas, como es natural cuando algo tan fino, noble y vulnerable, como el concepto de reformador, se pudre" ("Resultatet er blevet den dybeste Forvirring i de høieste Begreber, og den allerfarligste emoralisation, som naturligt er, naar noget saa Fiint og Ædelt og Zart som Begrebet "Reformator" forraadner." Kierkegaard, 1968-1978: XI 1 A 61/19972013: NB29:12). En realidad, el mundo se había aprovechado de Lutero para cambiar el significado de ser reformador; porque ahora ser reformador es salir bien librado. Según Kierkegaard, Lutero fue un reformador a medias (su vida también fue mediocre), haciéndolo imposible en el futuro. Como consecuencia, desde entonces ser mártir no es lo más elevado (Kierkegaard, 1968-1978: XI 1 A 61/1997-2013: NB29:12). Lutero, en vez de haber sido un verdadero mártir enfrentándose solitariamente en su tarea de la interiorización, hizo política creando partidarios de su causa (Kierkegaard, 1968-1978: X 5 A 121/1997-2013: NB28:32). Además, ni su predicación fue siempre clara, ni tampoco estuvo en concordancia con su vida (Kierkegaard, 1968-1978: X 2 A 263/1997-2013: NB14:88).

Como sabemos, las relaciones entre religión y política (influencias, condicionamientos entre las ideas y valores de una y otra) ha sido algo característico y problemático históricamente, especialmente con respecto a las grandes religiones monoteístas (judaísmo, cristianismo e islamismo); en ese sentido, aquí el concepto clave es el de "tolerancia" y cómo entenderla (Zalec-Pavlikova, 2019a: 39-48). Pero también son muy importantes las relaciones entre religión y sociedad, especialmente en nuestras actuales democracias en las que el ciudadano debe tener en cuenta unas virtudes cívicas, así como el papel de la religión en la vida pública. A este respecto, no es recomendable posicionamientos absolutamente excluyentes (al menos no sin una análisis detenido y profundo) entre vida privada y vida pública, entre deberes cívicos, democráticos y religiosos (Zalec-Pavlikova, 2019b: 75-84). En la actualidad, resulta interesante comprobar cómo se enfrentan, o se han enfrentado, los países poscomunistas a toda esta problemática, una vez que han recuperado sus libertades políticas (por ejemplo, en Eslovaquia, cf. Kardis-Valco, 2018: 95-107).

Volviendo a Lutero, y como ya he apuntado, la crítica a la cristiandad tiene que ver con otra de las condiciones del verdadero cristianismo: la imitación (Efterføgelse).

XLinguae, Volume 13 Issue 3, June 2020, ISSN 1337-8384, ISSN 2453-711X 
Según Kierkegaard, la cristiandad protestante había eliminado la imitación al sustituirla por la admiración (Kierkegaard, 1968-1978: X 3 A 750/1997-2013: NB22:128). Históricamente, desde el siglo III el cristianismo se había moderado existencialmente; y a partir del siglo IV se desorientó, al primar la admiración sobre la imitación de Jesucristo. De esa manera, quería evitarse el esfuerzo y la incomodidad de tener frente a sí ese Modelo absoluto. Tal táctica, pues, llevaba a prescindir de la imitación de Jesucristo. El resultado fue que el Hijo de Dios se convirtió en un mito (Kierkegaard, 1968-1978: X 4 A 148/1997-2013: NB23:144). Sin embargo, Cristo es el ideal y paradigma con el que tiene que relacionarse todo individuo singular, todo cristiano. El protestantismo, al alejarse del ideal y aferrarse a la comodidad, ha transformado el cristianismo en mitología, porque la diferencia se encuentra en la imitación. En ese sentido, Lutero y la Reforma lo tuvieron fácil, repito, puesto que la gente vio la posibilidad de escabullirse del esfuerzo del cristianismo (Kierkegaard, 1968-1978: X 4 A 354/1997-2013: NB24:105). Según Kierkegaard, la emancipación de la iglesia implica, religiosamente, la existencia de martirios (cruentos e incruentos). Incluso, en opinión de Kierkegaard, aquel que no sea un seguidor sufriente de Cristo, no puede pretender reformar la iglesia (como fue el caso de Lutero). Es un insulto contra el cristianismo querer emancipar a la iglesia por medio de votaciones, de la política, librándose así de los martirios (Kierkegaard, 1968-1978: X 4 A 22/19972013: NB23:22). Tal idea convierte al cristianismo en judaísmo y paganismo.

\section{El papel de la gracia divina}

Por otro lado, no hay que olvidar que el propio padre de la Reforma, Lutero, fue agustino. Y la misma concepción de la gracia en el protestantismo tiene su raíz en San Agustín (Kierkegaard, 1968-1978: X 5 A 121/1997-2013: NB28:32). Lutero enfatizó el valor de la gracia de Dios solo después de percatarse en sí mismo de la inutilidad de la ley. En el cristianismo de la Edad Media, y en el pensamiento de Lutero, la "ley" apunta al conjunto de aquellas prácticas ascéticas, como las plegarias, el ayuno, la mortificaciones de uno mismo, mediante las cuales el verdadero cristiano buscaba parecerse al propio Modelo: a ese Cristo que sufrió y fue crucificado. Sin embargo, lo acontecido es que los luteranos, perdiendo de vista el requerimiento de la ley, han aceptado la gracia en vano. La gracia, de hecho, no ha sido ofrecida al hombre para suprimir la ley, sino como una ayuda para cumplirla con las únicas y propias fuerzas. El cristiano, piensa Kierkegaard, debe esforzarse con todo su ser en imitar al Modelo. Todos debemos reconocer la infinita distancia con respecto al Modelo que pretendemos imitar. Pues hacernos conscientes de la infinita distancia que nos separa de él y, por consiguiente, a hacernos asimismo conscientes del infinito valor de la gracia que nos ha sido dada. La gracia se vuelve eficaz y útil solo con la condición de que el hombre experimente primero su propia insuficiencia o impotencia. En este sentido, Kierkegaard compara la condición de cada cristiano a aquella de un deudor insolvente al que le ha sido condonada una deuda infinitamente grande (Kierkegaard, 1968-1978: XI 2 A 286, XI 2 A 367/1997-2013: Papir 448:3, Papir 498). Tan grande que el deudor, aunque lo quisiera, no podría cancelarla nunca. Lo importante, sin embargo, es que el agradecido deudor (esto es, todos los seres humanos) conserve memoria del acreedor (Dios). Y el único modo de mostrar gratitud es, por ello, no olvidar la naturaleza de la deuda que le ha sido perdonada.

\section{Conclusiones}

Si bien puede considerarse a Lutero como un correctivo al cristianismo de su época, Kierkegaard, a su vez, también puede serlo con respecto al cristianismo luterano y protestante. La figura de Lutero, pese al respeto que expresa por ella Kierkegaard en sus Diarios, no escapa a la aguda crítica kierkegaardiana, mostrando por ello cierta ambigüedad hacia ella. Dicha crítica la realizó tomando como referente el cristianismo del Nuevo Testamento; o al menos, la interpretación que hace 
Kierkegaard de él. Por tanto, se trata de una crítica y correctivo cristianos, desde el interior del propio cristianismo, con un claro interés pedagógico, práctico, espiritual y no, pues, teórico o doctrinal.

El concepto de "correctivo" ("korrectiv" en danés, aunque Kierkegaard usó la forma latinizada "Correctiv"), no es un concepto muy estudiado en la investigación kierkegaardiana, pero resulta fundamental con relación a su crítica a la sociedad y cultura en general de su época. Según J. Michael Tilley (2014: 82), Kierkegaard usó este término en tres sentidos: a) filosófico; b) existencial; y c) con relación al orden establecido. En el primer sentido (filosófico), hay que entenderlo con respecto al idealismo especulativo; en el segundo b), con respecto a su tarea de llamar la atención sobre la importancia existencial de los ideales; y c) como consecuencia de los anteriores usos y sentidos, con respecto a su crítica al orden establecido de su época; en realidad, no se puede separar uno del otro. Obviamente, en lo que se refiere a lo tratado en nuestro artículo, hay que entender la crítica kierkegaardiana como un "correctivo" al orden establecido o Cristiandad (Christenheden); es decir, al falso cristianismo practicado, legitimado y representado por la Iglesia Nacional Danesa. No obstante, nos gustaría poner el énfasis en lo que se refiere al sentido de correctivo "existencial". A este respecto, me parece acertado el análisis que hace A.H. Khan (2018: 1-10) a la hora de valorar como más determinante o importante la investigación actual kierkegaardiana que trata de dar respuesta a los grandes retos actuales presentes en nuestro mundo desde una perspectiva existencial.

Para Kierkegaard, a Lutero no se le puede considerar ni un verdadero reformador, ni un mártir. Por tanto, tampoco un auténtico cristiano. Aunque en ese sentido, cabe preguntarse también si Kierkegaard lo fue. Para averiguarlo, hay que apelar a lo que manifiesta el Nuevo Testamento. A este respecto, podemos considerar al cristianismo, insisto, la más alta medida a la que se puede someter el ser humano. Como tal, exige la existencia de unas condiciones muy difíciles de llevarlas a la práctica, aunque no imposibles. Para ello debemos imitar a Jesucristo, seguir sus enseñanzas existencialmente, actuando con honestidad y lealtad, pero también con la fe puesta en la gracia divina. La relación entre Dios y el ser humano es fundamental; una relación que hay que entender como la de los lirios en el campo y las aves en el cielo, de sencillez, humildad y sacrificio. Y aunque exista una separación o heterogeneidad infinita entre Dios y el hombre, Jesucristo la hace cercana, ya que en Él se conjugan ambas naturalezas: la humana y la divina (es el camino, la verdad y la vida). Solo por Amor y para el Amor Dios se hizo hombre y se sacrificó para salvarnos. Ni Sócrates, ni Lutero, y ni siquiera Kierkegaard, pueden comparársele.

\section{Acknowledgment:}

This article was published with the support of International ScientificResearch Project: "Philosophy and religious studies and its meaning nowadays." Cooperation among: Sociedad Hispánica deAmigos de Kierkegaard, University of Granada (Spain) and Faculty of Humanities, University of Zilina in Zilina (Slovakia), 2020-2021.

\section{Bibliographic references}

BARRETT, L. 2012. Paul Tillich: an Ambivalent Appropriation, In: Kierkegaard's Influence on Theology, vol. I, J. Stewart (ed.), Farnham: Ashgate Publishing, pp. 335376. ISBN 9781409444787.

GARCIA MARTIN, J. 2011. The Ethical-Existential Demand of Kierkegaard's Single Individual: A Current Reading. In: Kierkegaard: East and West. Acta Kierkegaardiana, 2011. Toronto: Kierkegaard Circle, Trinity College, Universidad de Toronto, Ontario (Canada), pp. 203-214. ISBN 978-0-9809365-3-7. 
KARDIS, K. - VALCO, M. 2018. Future of Religious Faith. The Case of Present-Day Slovakia. In: European Journal of Science and Theology, vol. 14, n..4, pp. 95-107. ISSN 1841-0464.

KHAN, A. H. 2018. Kierkegaard Americanus: towards establishing a comparative analysis unit, In: XLinguae, vol. 11, n. 4, pp. 2-10. ISSN 1337-8384.

KIERKEGAARD, S. 1968-1978. Søren Kierkegaards Papirer. København: Gyldendal. Niels Thulstrup (ed.). Vol. I-XVI.

KIERKEGAARD, S. 1997-2013. Søren Kierkegaards Skrifter. Niels Jørgen Cappelørn, Joakim Garff, Johnny Kondrup, Tonny Aagaard Olesen og Steen Tullberg (eds.). København: Gads Forlag. Søren Kierkegaard Forskningscenteret. ISBN: 9788712031543

KIERKEGAARD, S. 2000. De los papeles de alguien que todavía vive. Sobre el concepto de ironía. Escritos Søren Kierkegaard. Volumen I. Madrid: Editorial Trotta. ISBN 84-8164-365-3.

KIERKEGAARD, S. 2006. El Instante. Madrid: Editorial Trotta. ISBN 978-84-8164867-6.

KIERKEGAARD, S. 2018. La dialéctica de la comunicación ética y ético-religiosa, Barcelona: Herder. ISBN 978-84-254-3923-0.

KONDRLA, P - DURKOVA, E. 2018. Interpersonal relations in ethics of science and technologies. In: Communications - Scientific Letters of the University of Zilina 20(1PartA), pp. 45-50. ISSN (print) 1335-4205, eISSN (online) 2585-7878.

MAHRIK, T. - VASBIEVA, D. - KRALIK, R - KONDRLA, P. 2020. Salvation as the teleological vector in Kierkegaard's practice in Christianity, In: European Journal of Science and Theology, vol.16, n. .4, pp.43-52. ISSN 1841-0464.

PAVLIKOVA, M. - ZALEC, B. 2019. Struggle for the Human Self and Authenticity: Kierkegaard's Critique of the Public, Established Order, Media, and False Christianity. In: Bogoslovni vestnik/Theological Quarterly, vol. 79, n. 4, pp. 10151026. ISSN 0006-5722.

PRENDER, R. 1981. Luther and Lutheranism. In: Kierkegaard and great traditions, Bibliotheca Kierkegaardiana 6, Copenhague: Reitzel, pp.121-172. ISBN 87-7421291-5.

SAEZ TAJAFUERCE, B. 1999. We want to see action! In: Kierkegaardiana 20. Copenhague: C.A. Reitzels Forlag, pp. 97-110. ISBN 87-7876-161-1.

SLØK, J. 1962. Kierkegaard and Luther. In H. A. Johnson and N. Thulstrup, A Kierkegaard Critique, Chicago: Henry Regnery Company, pp. 66-76. Library of Congress catalog card number: 62-7291.

SUANCES MARCOS, M. 1998. Søren Kierkegaard: vida de un filósofo atormentado. Madrid: UNED. ISBN 84-362-3607-6.

TAVILLA, I. 2017. Despair as eternal damnation of the self a biblical anthropolo-gy in outline European Journal of Science and Theology 13(3), pp. 163-173. ISSN 18410464.

TILLEY, J. M, 2014. Corrective. In: S. Emmanuel, W. McDonald and J. Stewart (eds.) Kierkegaard's Concepts. Tome II: Classicism to Enthusiasm, Farnham: Ashgate Publishing Limited, Volume II, pp. 81-86. ISBN. 9781472428394.

VALCO, M. 2017. The Value of Dietrich Bonhoeffer's Theological-Ethical Reading of Søren Kierkegaard. In: European Journal of Science and Theology, vol. 13, no.1, pp. 47-58, ISSN 1841-0464.

ZALEC, B. 2018. Religous tolerance and christianizy. In: Bogoslovni Vestnik, vol. 78, n. 2, pp. 235-334. ISSN 0006-5722.

ZALEC, B. - PAVLIKOVA, M. 2019a. Religious Tolerance and Intolerance. In: European Journal of Science and Theology, vol. 15, n. 5, pp. 39-48, ISSN 1841-0464. ZALEC, B. - PAVLIKOVA, M. 2019b. Civic Virtues and Functions of Religion in Public Life. In: European Journal of Science and Theology, vol. 15, n. 6, pp. 75-84, ISSN 1841-0464. 
Words: 4854

Characters: 32495 (18,05 standard pages)

Prof. Dr. Jose Garcia Martin

Departamento de Sociologia

Universidad de Granada,

España

jgarciamartin@ugr.es

Assoc. prof. Dinara G. Vasbieva, PhD

Foreign Languages Department Financial University under the Government of the Russian Federation

Leningradsky prospect 49125993 Moscow

Russia

dinara-va@list.ru

PhDr. Jozef Polacko, PhD., MBA

Department of Social Sciences

College of International Business ISM Slovakia in Presov,

Slovakia

admin@ismpo.sk

ThDr. Hedviga Tkacova, $\mathrm{PhD}$

University of Zilina in Zilina

Faculty of Humanities

Univerzitna 8215/1, 01026 Zilina

Slovakia

hedviga.tkacova@fhv.uniza.sk 